\title{
INTEGRAÇÃO AGRICULTURA-PECUÁRIA EM PLANTIO DIRETO: PRODUÇÃO DE FORRAGEM E RESÍDUO DE PALHA APÓS PASTEJO
}

\author{
LUIZ M. M. DE MELLO ${ }^{1}$, ÉLCIO H. YANO ${ }^{2}$, KAREM C. P. NARIMATSU ${ }^{3}$, \\ CELSO M. TAKAHASHI ${ }^{4}$, ÉMERSON BORGHI ${ }^{2}$
}

\begin{abstract}
RESUMO: O objetivo deste trabalho foi verificar, no sistema integração agricultura-pecuária, a possibilidade de utilizar uma cultura para pastejo cujos resíduos permitam produção de palha suficiente para a manutenção do plantio direto, bem como avaliar a produção da forrageira e do resíduo em diferentes distâncias em relação ao centro do pivô, em três épocas, e o desempenho econômico do sistema. Avaliaram-se o impacto do pastejo rotacionado de sorgo forrageiro em plantio direto, sob irrigação em um pivô central de 75 ha, sobre a produção de matéria seca do sorgo forrageiro, a quantidade de resíduos, o custo de produção e o ganho de peso animal. $O$ ensaio foi conduzido num Latossolo Vermelho Distrófico. O delineamento experimental utilizado foi o de blocos ao acaso, com parcelas subdivididas, com quatro tratamentos principais: locais de amostragem em diferentes distâncias em relação ao centro do pivô; três tratamentos secundários (ciclos de pastejos) e sete repetições (sete piquetes de 9,37 ha para pastejo, dispostos na forma de "pizza"). Os resultados permitiram concluir que: a produção do sorgo forrageiro foi suficiente para permitir um ganho $621 \mathrm{~kg} \mathrm{ha}^{-1}$ de peso vivo e a quantidade de resíduos de sorgo após o pastejo foi suficiente para suprir o aporte anual de matéria seca de palha necessária para a manutenção do plantio direto; a área, após os pastejos, continuou passível de ser explorada no sistema de plantio direto, e o sistema pesquisado mostrou-se técnica e economicamente viável.
\end{abstract}

PALAVRAS-CHAVE: sorgo forrageiro, pastejo rotacionado, produção de palha.

\section{INTEGRATION AGRICULTURE-PASTURE IN NO-TILLAGE SYSTEM: FORAGE YIELD AND MULCH RESIDUE AFTER ANIMAL GRAZING}

SUMMARY: The objective of this research was to verify, in an integrated agriculture-pasture system, the viability of using a pasture crop which residue allow enough mulch for a no-tillage system management. Forage yield and residue at different distances from a central pivot, in three periods, and an economical analysis of the system were also evaluated. The impact of rotating grazing, in a 75 ha no-tillage sorghum forage system, irrigated by a central pivot, on forage sorghum dry matter yield, mulch residues and animal weight gain were evaluated. The site presented a dystrophic, dark red "latossol" (oxisol). The experimental design was a split plot, with four main (sampling points at different distances from the central of the pivot) and three secondary (grazing periods) treatments, with seven replications (seven 9.37 ha paddocks for grazing, in a pizza-like shape). Forage sorghum allowed a $621 \mathrm{~kg} \mathrm{ha}^{-1}$ gain in live weight and the volume of sorghum mulch left after grazing was enough to sustain a no-tillage system. The area, even after grazing, provided conditions to be used in the no-tillage system, proving technically and economically feasible.

KEYWORDS: sorghum forage, rotating grazing, mulch production.

\footnotetext{
${ }^{1}$ Professor Adjunto, DEFERS, Faculdade de Engenharia de Ilha Solteira, UNESP, Av. Brasil, 56, Ilha Solteira - SP, Fone: (0XX18) 3743.1143 ramal: 1738, e-mail: malcolm@agr.feis.unesp.br.

${ }^{2}$ Aluno do programa de pós-graduação Energia na Agricultura, FCA/Unesp, Botucatu - SP.

${ }^{3}$ Aluna do curso de graduação em Agronomia, Faculdade de Engenharia, UNESP/Ilha Solteira - SP.

${ }^{4}$ Engenheiro Agrônomo pela Faculdade de Engenharia, UNESP/Ilha Solteira - SP.

Recebido pelo Conselho Editorial em: 30-4-2002

Aprovado pelo Conselho Editorial em: 5-11-2003
} 


\section{INTRODUÇÃO}

Uma prática que tem contribuído para a viabilização econômica das propriedades rurais e para o próprio plantio direto é a integração agricultura-pecuária, que pode ser definida como sendo o sistema que integra as duas atividades com os objetivos de maximizar racionalmente o uso da terra, da infraestrutura e da mão-de-obra, diversificar e verticalizar a produção, minimizar custos, diluir os riscos e agregar valores aos produtos agropecuários, por meio dos recursos e benefícios que uma atividade proporciona à outra. Dentro desse conceito, as áreas de lavouras dão suporte à pecuária por meio da produção de alimentação animal, seja na forma de grãos, silagem e feno, seja na de pastejo direto, e aumenta a capacidade de suporte da propriedade, permitindo a venda de animais na entressafra e proporcionando melhor distribuição de receita durante o ano.

De acordo com SALTON (1999), as culturas de safrinha outono/inverno são fundamentais para a implantação e viabilização do sistema de plantio direto, por proporcionarem cobertura permanente do solo, rotação de culturas, diversificação de receitas e diluição dos riscos. Conforme BAYER (1996) \& FIORIN (1999), citados por AMADO (2000), o aporte anual de palha para o plantio direto deve ser de 10 a $12 \mathrm{t} \mathrm{ha}^{-1}$. De acordo com HECKLER et al. (1998), as principais fontes de palha para o plantio direto são as gramíneas e, dentre elas, têm se destacado o milho e o sorgo como boas culturas formadoras de cobertura.

Para BOLLER \& GAMERO (1997), o aproveitamento de parte da biomassa das culturas de inverno, para alimentação animal, pode equilibrar o balanço energético e melhorar o desempenho econômico de sistemas conservacionistas do solo. URCHEI et al. (1998) comentam que, em área irrigada, o plantio direto apresenta economia de água e energia; e nessas condições, as pastagens de aveia e milheto permitiram ganho de 0,7 a $1,0 \mathrm{~kg}$ de peso vivo/animal/dia. Segundo ROCHA (2000), sistemas de produção baseados na integração agricultura/pecuária permitem a diluição dos custos fixos da propriedade, a obtenção de receita distribuída durante o ano e o melhor aproveitamento da mão-deobra especializada.

Quando são utilizadas culturas para a cobertura do solo, pouco se sabe sobre qual o melhor manejo dessa palhada, podendo ser utilizada para alimentação animal na forma de silagem, feno e pastejo direto (LEVIEN, 1999).

GILLEN et al. (1984) e IRVING et al. (1995) estudaram o comportamento de bovinos em sistema de pastejo rotacionado e observaram que os animais preferiram alimentar-se em áreas com distância de até $200 \mathrm{~m}$ da água e evitaram áreas mais distantes, atribuindo esse comportamento à freqüência com que os animais utilizaram a água.

Para o pastejo direto, as culturas mais utilizadas, até então, têm sido o milheto e a aveia-preta, ou os próprios resíduos das culturas de verão colhidas para grãos. Recentemente, tem-se utilizado o sorgo forrageiro para pastejo e, após a retirada dos animais, espera-se a rebrota do sorgo, que é dessecado com a finalidade de formação de palha. Normalmente, o milheto e a aveia, por apresentarem custos mais baixos, são pastejados em pastos de maior tamanho sem sistematização do uso. Já o sorgo, por ser mais exigente e apresentar maior custo, tem sido pastejado dentro de critérios técnicos que proporcionam melhor aproveitamento da forragem, como o sistema rotacionado com alta lotação animal.

Por tratar-se de um sistema novo, existem questionamentos de ordem geral a respeito da Integração Agricultura-Pecuária; os mais freqüentes são em relação à compactação do solo, seus efeitos na cultura seguinte e sobre a quantidade de resíduos de palha para a cobertura do solo, além de questionamentos sobre o ganho de peso dos animais e o desempenho financeiro do sistema. Diversos produtores têm relatado que, em pastejo rotacionado irrigado por pivô central, com piquetes divididos em forma de "pizza" e com alta lotação animal, ocorre a diminuição da população da forrageira nas 
áreas próximas ao centro do pivô, onde se localizam os bebedouros e os cochos de sal, denominadas de áreas de "lazer". Atribuem a queda da produção da pastagem ao fato de que, nessas áreas, além de serem mais estreitas, ocorre maior trânsito dos animais ao dirigirem-se aos bebedouros, causando maior compactação do solo.

O objetivo deste trabalho foi verificar, no sistema integração agricultura-pecuária, a possibilidade de utilizar uma cultura para pastejo cujos resíduos permitam produção de palha suficiente para a manutenção do plantio direto, bem como avaliar a produção da forrageira e do resíduo em diferentes distâncias em relação ao centro do pivô, em três épocas, e o desempenho econômico do sistema.

\section{MATERIAL E MÉTODOS}

O ensaio foi conduzido na Fazenda Bonança - Pecuária Damha, município de Pereira Barreto SP, à margem direita do lago da Usina Hidrelétrica de Três Irmãos, localizada no Rio Tietê. A área apresenta coordenadas geográficas $20^{\circ} 40^{\prime}$ de latitude sul e $50^{\circ} 01^{\prime}$ de longitude oeste, altitude média de $345 \mathrm{~m}$, precipitação média anual de $1.200 \mathrm{~mm}$, temperatura média anual de $24,1^{\circ} \mathrm{C}$ e clima do tipo Aw, segundo o critério de Köeppen.

O solo da área experimental foi classificado como Latossolo Vermelho Distrófico, textura média, A moderado, relevo plano e suave ondulado (OLIVEIRA et al., 1999), com declividade média de $0,03 \mathrm{~m} \mathrm{~m}^{-1}$. A análise granulométrica do solo apresentou a seguinte composição: $160 \mathrm{~g} \mathrm{~kg}^{-1}$ de argila, $800 \mathrm{~g} \mathrm{~kg}^{-1}$ de areia e $40 \mathrm{~g} \mathrm{~kg}^{-1}$ de silte, na profundidade de $0-20 \mathrm{~cm}$. O resultado da análise química do solo, antes da instalação do ensaio, encontra-se na Tabela 1.

TABELA 1. Análise química do solo da área experimental, na profundidade de $0-20 \mathrm{~cm}$, antes da instalação do ensaio.

\begin{tabular}{cccccccccc}
\hline \multirow{2}{*}{ Repetições } & $\begin{array}{c}\text { P-resina } \\
\left(\mathrm{mg} \mathrm{dm}^{-3}\right)\end{array}$ & $\begin{array}{c}\mathrm{M} . \mathrm{O} . \\
\left(\mathrm{g} \mathrm{dm}^{-3}\right)\end{array}$ & $\begin{array}{c}\mathrm{pH} \\
\left(\mathrm{CaCl}_{2}\right)\end{array}$ & $\mathrm{K}$ & $\mathrm{Ca}$ & $\mathrm{Mg}$ & $\mathrm{H}+\mathrm{Al}$ & $\mathrm{Al}$ & $\mathrm{V}$ \\
\cline { 6 - 7 } & \multicolumn{2}{c}{$\mathrm{mmol}_{\mathrm{c}} \mathrm{dm}^{-3}$} & & & $\%$ \\
\hline 1 & 28 & 22 & 5,2 & 0,9 & 20 & 8 & 18 & 0 & 61 \\
3 & 17 & 26 & 5,0 & 1,1 & 16 & 7 & 18 & 1 & 57 \\
4 & 37 & 21 & 4,9 & 0,8 & 14 & 5 & 18 & 1 & 53 \\
5 & 38 & 21 & 5,1 & 0,9 & 14 & 6 & 18 & 0 & 53 \\
6 & 43 & 32 & 5,2 & 0,7 & 21 & 9 & 18 & 0 & 63 \\
7 & 24 & 26 & 5,1 & 0,5 & 16 & 7 & 20 & 0 & 54 \\
\hline Médias & 19 & 23 & 4,7 & 0,5 & 12 & 5 & 20 & 1 & 48 \\
\hline
\end{tabular}

O delineamento experimental utilizado foi o de blocos ao acaso, com parcelas subdivididas, com quatro tratamentos principais, três tratamentos secundários e sete repetições. $\mathrm{O}$ ensaio ocupou uma área de 75 ha irrigada por pivô central de 488,6 m de raio, que há três anos vinha sendo cultivada em plantio direto.

A área foi semeada com o sorgo forrageiro para pastejo, de marca comercial AGROCERES cultivar AG 2501, e dividida em oito piquetes de 9,37 ha, para pastejo rotacionado, dispostos em forma de "pizza". Para fins de amostragens, foram utilizados sete piquetes no ensaio, cada um deles considerado uma repetição, embora os oito piquetes tenham sido pastejados. Durante o desenvolvimento do ensaio, foram realizados três ciclos de pastejo, com permanência dos animais por 3,5 dias por piquete e intervalo de 28 dias entre um ciclo e outro em um mesmo piquete. 
Os tratamentos principais foram formados por quatro diferentes locais de amostragem dentro de cada piquete, localizados nas seguintes distâncias em relação ao centro do pivô: A - 380 a 488 m, B - 271 a $380 \mathrm{~ms}, \mathrm{C}$ - de 160 a $271 \mathrm{~m}$ e D - de 45 a $160 \mathrm{~m}$.Os tratamentos secundários foram constituídos por três épocas de amostragem ( $\left(1^{\circ}, 2^{\circ}\right.$ e $3^{\circ}$ pastejos $)$.

No centro do pivô, foi montada uma área de "lazer" de 0,64 ha ( $45 \mathrm{~m}$ de raio), com bebedouros e cochos para sal. O perímetro da área experimental (pivô), a área de lazer e as divisões entre os piquetes foram cercados com cerca eletrificada de dois fios. Não foi realizada a irrigação no piquete que estava sendo ocupado por animais para evitar o aumento da compactação. O primeiro ciclo de pastejo foi realizado no período de 3 a 30-11-2000, o segundo ciclo de $1^{\underline{0}}$ a 28-12-2000 e o terceiro de 29-12-2000 a 25-1-2001. No período do experimento, os animas alimentaram-se do pastejo do sorgo e receberam suplementação mineral e água no cocho, não tendo acesso a nenhuma outra fonte de alimentos.

$\mathrm{Na}$ Figura 1, ilustra-se o croqui da área experimental com as divisões dos piquetes e a locação dos pontos de amostragens.

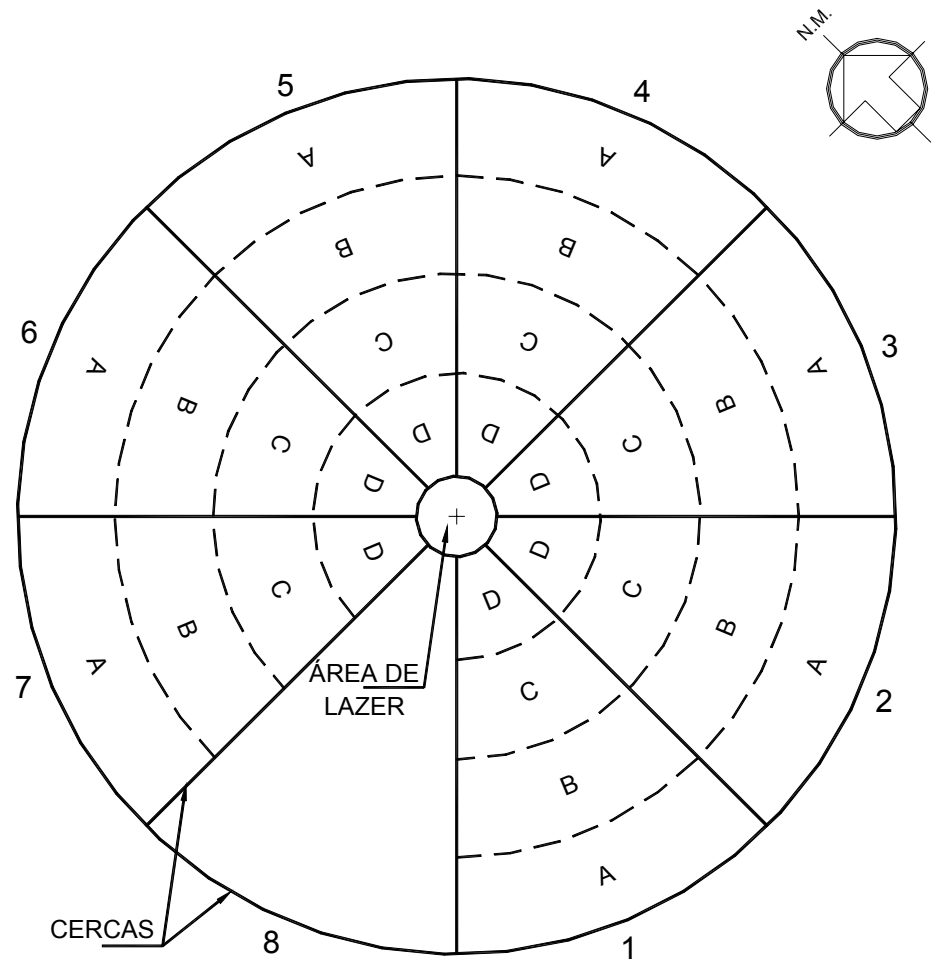

Piquetes de 1 a 7 - repetições

Piquete 8 - testes de máquinas

A, B, C e D - locais de amostragem (tratamentos principais)

FIGURA 1. Croqui da área experimental.

Para a eliminação da vegetação existente (guandu e plantas daninhas), a área experimental foi dessecada por meio da aplicação do herbicida glifosate $\left(0,75 \mathrm{~kg} \mathrm{ha}^{-1}\right.$ de p.a.), com volume de aplicação de $80 \mathrm{~L}$ de calda por hectare, em pulverização tratorizada. O sorgo foi semeado com semeadoraadubadora de marca Marchesan, modelo Suprema D-44, pneumática, com seis linhas espaçadas entre si de $0,6 \mathrm{~m}$, configurada para plantio direto, sendo cada linha de semeadura composta por: disco liso de corte de palha com $17 \mathrm{~cm}$ de diâmetro, disco duplo desencontrado para abertura de sulco e deposição de adubo, disco duplo defasado para deposição de sementes, roda compactadora e roda limitadora de profundidade. 
Para a adubação de plantio, foi utilizada a fórmula 8-28-16 na dose de $165 \mathrm{~kg} \mathrm{ha}^{-1}$ no sulco de semeadura. Foram efetuadas três adubações de cobertura, por meio de fertirrigação, sendo a primeira no intervalo entre a semeadura e o primeiro pastejo, utilizando-se de $40 \mathrm{~kg} \mathrm{ha}^{-1}$ de $\mathrm{N}$ na forma de uran $+15 \mathrm{~kg} \mathrm{ha}^{-1}$ de $\mathrm{K}_{2} \mathrm{O}$ na forma de cloreto de potássio. A segunda adubação de cobertura foi efetuada entre o primeiro e o segundo pastejo, com $33 \mathrm{~kg} \mathrm{ha}^{-1}$ de $\mathrm{N}$ na forma de uran e a terceira cobertura efetuada com $30 \mathrm{~kg} \mathrm{ha}^{-1}$ de $\mathrm{N}$ na forma de nitrato de amônio, entre o segundo e o terceiro pastejo. A produção de matéria seca foi avaliada um dia antes de cada pastejo para quantificar a produção da biomassa da cultura do sorgo em cada ciclo de pastejo. Essas avaliações foram efetuadas nos quatro tratamentos de amostragem (A, B, C e D) de cada piquete. Para tanto, foram coletadas três subamostras de $1 \mathrm{~m}^{2}$ em cada repetição. As amostras foram picadas e pesadas, determinando-se a matéria verde e, em seguida, submetidas em estufa de circulação forçada de ar a $105^{\circ} \mathrm{C}$, por $12 \mathrm{~h}$, e novamente pesadas para a determinação da matéria seca. Após cada pastejo, a vegetação remanescente foi rebaixada com rolo- facas e para as amostragens do resíduo foi retirado todo o material da superfície do solo em uma área de $16 \mathrm{~m}^{2}$ ( 4 x $4 \mathrm{~m}$ ) em cada ponto de amostragem, um dia antes de cada pastejo, para evitar a coleta de material remanescente de pastejo anterior. O resíduo coletado foi pesado, determinando-se a matéria verde e em seguida secado em estufa a $105^{\circ} \mathrm{C}$, por $12 \mathrm{~h}$, para a determinação da matéria seca.

Os animais utilizados foram garrotes, da raça nelore, com $221 \mathrm{~kg}$ de peso vivo, no início do experimento. A lotação foi de 1.100 animais no primeiro pastejo, 800 animais no segundo e 500 animais no terceiro pastejo. Um dia antes do primeiro pastejo, os animais foram pesados e cadastrados através de brincos numerados, colocados na orelha. Devido à necessidade de ajustar a lotação à disponibilidade de forragem, alguns animais foram retirados da área no final do primeiro e segundo pastejos e pesados, tendo seu peso registrado em planilha. Os animais que permaneceram na área experimental até o final do ensaio foram pesados um dia após o último pastejo. Para o cálculo do ganho médio de peso vivo, foi considerado o ganho individual durante o período de permanência de cada animal e calculada a média ponderada do ganho de peso vivo durante o ensaio. Antes de cada pesagem, os animais foram submetidos a jejum de $12 \mathrm{~h}$, visando a padronizar as duas pesagens. As pesagens foram realizadas em balança eletrônica computadorizada, e os arquivos foram armazenados em planilhas da própria balança.

A análise econômica foi realizada considerando-se os custos de produção do sorgo e o valor da produção de carne. Os custos foram calculados com base nos valores vigentes no mercado no mês de maio-2001, fornecidos pelo Departamento de Compras da Pecuária Damha. Dessa forma, procurou-se obter os custos reais da produção da área experimental. $\mathrm{O}$ valor da produção foi calculado em função do preço médio da arroba do boi na primeira quinzena do mês de maio-2001, obtido junto aos frigoríficos da região. O valor do dólar oficial em 15-5-2001era R \$ 2,34 (NEHMI et al., 2002).

No custo de produção, foram considerados os custos de insumos, mão-de-obra, operações mecanizadas (fixos e variáveis), infra-estrutura (fixos e variáveis) e irrigação (fixos e variáveis). Utilizou-se da taxa de juros de $8,75 \%$ a.a. (FINAME RURAL) e a vida útil dos equipamentos de 15 anos para pivô central e 10 anos para máquinas agrícolas e infra-estrutura (cochos, bebedouros e cercas). Não foram considerados os custos de remuneração do capital da terra e dos animais.

\section{RESULTADOS E DISCUSSÃO}

Conforme apresentado na Tabela 2, os valores de produção de massa seca do sorgo, referentes às épocas, diferiram estatisticamente entre si, mostrando uma redução de produção no decorrer dos pastejos. O primeiro pastejo apresentou maiores produções e o terceiro, os menores valores. De maneira geral, era esperada a redução de produção de um pastejo para o outro, pois, apesar de perfilhar nesse intervalo, parte das plantas de sorgo morreram com o pisoteio dos animais e outras floresceram, 
completando seu ciclo de vida. Não houve diferenças significativas na quantidade de resíduos entre os pastejos, indicando que houve uma pressão de pastejo adequada nas três épocas.

TABELA 2. Valores médios de massa seca $\left(\mathrm{kg} \mathrm{ha}^{-1}\right)$ da produção e do resíduo de sorgo AG $2501 \mathrm{em}$ três pastejos.

\begin{tabular}{ccccc}
\hline \multirow{2}{*}{ Parâmetros } & \multicolumn{4}{c}{ Épocas } \\
\cline { 2 - 5 } & $1^{0}$ Pastejo & $2^{\underline{0}}$ Pastejo & $3^{0}$ Pastejo & Média \\
\hline Produção & $9.739 \mathrm{a}$ & $6.845 \mathrm{~b}$ & $4.732 \mathrm{c}$ & 7.105 \\
Resíduo & $3.980 \mathrm{a}$ & $3.370 \mathrm{a}$ & $3.263 \mathrm{a}$ & 3.538 \\
\hline
\end{tabular}

C.V. Produção $=26,75 \% \quad$ C.V. Resíduo $=31,15 \%$

Médias seguidas da mesma letra nas linhas não diferem significativamente entre si, a $5 \%$ de probabilidade (Tukey).

Em relação aos locais de amostragem (Tabela 3), os mesmos não mostraram diferenças significativas entre si no que diz respeito à produção do sorgo, porém a produção de resíduos foi menor nos locais mais próximos ao centro do pivô, no qual se encontram os bebedouros e cochos de sal, mostrando que os animais se alimentam mais nos pontos próximos aos bebedouros. Os resultados confirmam as observações de GILLEN et al. (1984) \& IRVING et al. (1995), que estudaram o comportamento de bovinos em sistemas de pastejo rotacionado e observaram que os animais preferiram alimentar-se em áreas mais próximas da água e evitaram áreas mais distantes, atribuindo este comportamento à freqüência com que os animais utilizaram a água.

TABELA 3. Valores médios de massa seca $\left(\mathrm{kg} \mathrm{ha}^{-1}\right)$ da produção e do resíduo de sorgo AG 2501 em função dos locais de amostragem.

\begin{tabular}{cccccc}
\hline \multirow{2}{*}{ Parâmetros } & \multicolumn{5}{c}{ Local } \\
\cline { 2 - 6 } & $\mathrm{A}$ & $\mathrm{B}$ & $\mathrm{C}$ & $\mathrm{D}$ & Média \\
\hline Produção & $7.832 \mathrm{a}$ & $7.330 \mathrm{a}$ & $6.762 \mathrm{a}$ & $6.499 \mathrm{a}$ & 7.106 \\
Resíduo & $4.470 \mathrm{a}$ & $3.736 \mathrm{ab}$ & $3.233 \mathrm{~b}$ & $2.712 \mathrm{~b}$ & 3.538 \\
\hline
\end{tabular}

C.V. $=11,88 \% \quad$ C.V. Resíduo $=18,42 \%$

Médias seguidas da mesma letra nas linhas não diferem significativamente entre si, a 5\% de probabilidade (Tukey).

Os resultados anteriores também ficam evidentes na análise da Tabela 4, na qual se nota que a produção acumulada de sorgo não variou significativamente em função dos locais de amostragem, porém a quantidade de resíduos acumulados, após os três pastejos, mostrou-se estatisticamente menor nos pontos próximos ao centro do pivô. A quantidade acumulada de massa seca de resíduos, nesse sistema, por si só, foi suficiente para suprir a quantidade de palha que deve ser adicionada anualmente à superfície do solo para que o plantio direto tenha condição de manifestar seu potencial como sistema sustentável; pois, segundo BAYER (1996) \& FIORIN (1999), citados por AMADO (2000), esse aporte anual de resíduos deve ser da ordem de $10 \mathrm{tha}^{-1}$.

TABELA 4. Valores médios de massa seca $\left(\mathrm{kg} \mathrm{ha}^{-1}\right)$ da produção e do resíduo de sorgo AG2501, acumulados em três pastejos, em função do local de amostragem.

\begin{tabular}{ccc}
\hline Local & Produção Acumulada & Resíduo Acumulado \\
\hline A & $23.495 \mathrm{a}$ & $10.632 \mathrm{ab}$ \\
B & $21.989 \mathrm{a}$ & $11.206 \mathrm{a}$ \\
C & $19.464 \mathrm{a}$ & $9.653 \mathrm{ab}$ \\
D & $20.088 \mathrm{a}$ & $7.939 \mathrm{~b}$ \\
\hline Média & 21.259 & 9.858 \\
\hline C.V. (\%) & 11,48 & 17,96 \\
\hline
\end{tabular}

Médias seguidas da mesma letra nas colunas não diferem significativamente entre si, a 5\% de probabilidade (Tukey). 
A análise do custo de produção apresentada na Tabela 5 revela que esse é um sistema altamente dependente de insumos (51,96\% do custo), principalmente de fertilizantes. A irrigação contribuiu consideravelmente na elevação dos custos, respondendo por 34,95\%; porém, devemos considerar que esse foi um período com distribuição irregular de chuvas, necessitando de irrigação por 759 horas durante o período em questão, quantidade que, normalmente, não é utilizada nessa época em anos de distribuição normal de chuvas, situação em que o custo de produção seria reduzido com conseqüente aumento da receita líquida.

A mão-de-obra representou um pequeno porcentual do custo de produção $(4,94 \%)$, mostrando que foi viável utilizar a mão-de-obra da propriedade na diversificação de atividades sem comprometimento do desempenho econômico.

TABELA 5. Custo de produção de 1,0 ha de sorgo forrageiro irrigado para pastejo rotacionado.

\begin{tabular}{lcc}
\hline Discriminação & $\mathrm{R} \$$ & $\%$ \\
\hline 1. Custo de insumos & & \\
Fertilizantes de plantio & 89,28 & 14,66 \\
Fertilizantes de cobertura & 101,77 & 16,72 \\
Sementes & 38,94 & 6,40 \\
Inseticidas & 13,37 & 3,2 \\
Herbicida & 22,57 & 3,7 \\
Sal, medicamentos e vacinas & 50,40 & 8,28 \\
Subtotal & 316,33 & 51,96 \\
2. Custo de operações mecanizadas & & \\
Aplicação de herbicidas & 5,40 & 0,89 \\
Semeadura & 22,27 & 3,65 \\
Subtotal & 27,67 & 4,54 \\
3. Custo da irrigação (759 horas) & & \\
Custos fixos & 98,67 & 16,20 \\
Reparo e manutenção & 19,44 & 3,19 \\
Energia & 94,70 & 15,56 \\
Subtotal & 212,81 & 34,95 \\
Custo de infra-estrutura & 21,90 & 3,6 \\
Custo de mão-de-obra & 30,06 & 4,94 \\
\hline TOTAL & 608,77 & 100,00 \\
\hline
\end{tabular}

Obs: US\$ $1,0=\mathrm{R} \$ 2,34$

A lotação animal na área experimental foi de 1.100 cabeças no primeiro pastejo; 800 cabeças no segundo pastejo e 500 cabeças no terceiro pastejo. O ganho médio de peso vivo durante os três pastejos foi de $0,7 \mathrm{~kg} /$ animal/dia, totalizando um ganho de $46.600 \mathrm{~kg}$ de peso vivo nos 75 ha; considerando um rendimento médio de carcaça de $52 \%$, o ganho foi de $23.951 \mathrm{~kg}$ de carne nos 75 ha, correspondendo a $319 \mathrm{~kg}$ ou 21,3 arrobas de carne ha ${ }^{-1}$. Considerando o preço da arroba do boi de $\mathrm{R} \$ 41,00$, a receita bruta gerada no sistema foi de $\mathrm{R} \$ 872,48 \mathrm{ha}^{-1}$.

A análise econômica da produção (Tabela 6) mostra que o sistema foi economicamente viável, gerando uma receita líquida de $\mathrm{R} \$ 263,71 \mathrm{ha}^{-1}$; com relação benefício/custo de 1,43 e índice de lucratividade de 30,2\%. Nesse sistema, além dos benefícios indiretos, devido aos resíduos do sorgo, houve a geração direta de receita, o que não ocorre quando são plantadas culturas exclusivamente para fins de formação de palha, situação em que os benefícios são indiretos e manifestam-se por meio das culturas seqüentes. 
TABELA 6. Análise econômica da produção.

\begin{tabular}{lc}
\hline Discriminação & $\mathrm{R} \$$ ha $^{-1}$ \\
\hline A - Custo & 608,77 \\
B - Receita bruta & 872,48 \\
C - Receita líquida (B-A) & 263,71 \\
\hline Benefício/Custo (B/A) & 1,43 \\
Índice de lucratividade (C/B 100) & $30,2 \%$ \\
\hline
\end{tabular}

Os resultados indicam que é possível praticar a integração agricultura-pecuária com pastejo, pois a produção do sorgo produziu resíduos após os pastejos, em quantidades suficientes para a proteção do solo, além de proporcionar a geração de receita por meio do ganho de peso dos animais, contribuindo, dessa forma, com o desempenho econômico do sistema, conforme preconizado por BOLLER \& GAMERO (1997).

\section{CONCLUSÕES}

A quantidade de resíduos de sorgo deixados sobre o solo após os três pastejos foi suficiente para suprir o aporte anual de massa seca de palha, necessário para a manutenção do plantio direto. A área continuou passível de ser explorada no sistema de plantio direto. O sistema estudado mostrou-se técnica e economicamente viável.

\section{REFERÊNCIAS BIBLIOGRÁFICAS}

AMADO, T.J. Manejo da palha, dinâmica da matéria orgânica e ciclagem de nutrientes em plantio direto. In: ENCONTRO NACIONAL DE PLANTIO DIRETO NA PALHA, 7., 2000, Foz do Iguaçu. Resumos... Foz do Iguaçu: Federação Brasileira de Plantio Direto na Palha, 2000. p.105-11.

BOLLER, W.; GAMERO, C.A. Estimativa dos custos econômicos e energéticos de sistemas de preparo e de manejo do solo para a cultura do feijão. Energia na agricultura, Botucatu, v.12, n.2, p.2638, 1997.

GILLEN, R.L.; KRUEGER, W.C.; MILLER, R.F. Cattle distribution on mountain rangeland in northeastern Oregon. Journal Range Manage, Denver, v.37, p.549-53, 1984.

HECKLER, J.C.; HERNANI, L.C.; PITOL, C. Palha. In: SALTON, J.C.; HERNANI, L.C.; FONTES, C.Z. Sistema de plantio direto: o produtor pergunta, a Embrapa responde. Dourados: Embrapa-SPI, 1998. p.38-49.

IRVING, B.D.; RUTLEDGE, P.L.; BAILEY, A.W.; ANNE NAETH, M.; CHANSYK, D.C. Grass utilization and grazing distribution within intensively managed fields in Central Alberta. Journal Range Manage, Denver, v.48, n.4, p.358-61, 1995.

LEVIEN, R. Condições de cobertura e métodos de preparo do solo para a implantação da cultura do milho (Zea mays L.).1999. 305 f. Tese (Doutorado em Energia na Agricultura) - Universidade Estadual Paulista, Faculdade de Ciências Agronômicas, Botucatu, 1999.

NEHMI, I.M.D.; FERRAZ, J.V.; NEHMI FILHO, V.A. AGRIANUAL 2003: Anuário estatístico da agricultura brasileira. São Paulo: FNP Argos Comunicação, 2002. p.167.

OLIVEIRA, J.B.; CAMARGO, M.N.; CALDERANO FILHO, B. Mapa pedológico do Estado de São Paulo: legenda expandida. Campinas: EMBRAPA/IAC, 1999. 64 p. 
ROCHA, E.L.C. Plantio direto e integração lavoura-pecuária no cerrado. In: ENCONTRO

NACIONAL DE PLANTIO DIRETO NA PALHA, 7., 2000, Foz do Iguaçu. Resumos... Foz do Iguaçu: Federação Brasileira de Plantio Direto na Palha, 2000. p.118.

SALTON, J.C. Alterações em atributos físicos do solo decorrentes da rotação soja-pastagem, no sistema plantio direto. Dourados: EMBRAPA, 1999. Não paginado. (Comunicado Técnico, 10).

URCHEI, M.A.; MOREIRA, J.A.A.; STONE, L.F.; ALVARENGA, R.C. Água e temperatura do solo. In: SALTON, J.C.; HERNANI, L.C.; FONTES, C.Z. Sistema de plantio direto: o produtor pergunta, a Embrapa responde. Dourados: Embrapa-SPI, 1998. p.81-101. 